Ivanova, A., Marinova I. (2020). Role of colours in historical buildings preservation. Eurasia: Current Issues of Cultural Heritage. European Scientific e-Journal, 3(3), 89-96. Hlučín-Bobrovníky: “Anisiia Tomanek” OSVČ.

DOI: $10.47451 /$ her2020-12-004

The paper is published in Crossref, ICI Copernic, BASE, Zenodo, OpenAIRE, LORY, HSLU, J-Gate, Academic Resource Index ResearchBib, ISI International Scientific Indexing, eLibrary, Mendeley, and WebArchive databases.

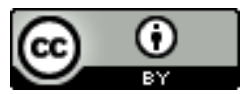

Alexandra Ivanova, Associate Professor, Doctor of Art Sciences, Department of Architecture, High School for Building Construction "Ljuben Karavelov". Sofia, Bulgaria.

Ivanka Marinova, Assistant Professor, Doctor of Architectural Sciences, Department of Architecture, High School for Building Construction "Ljuben Karavelov". Sofia, Bulgaria.

\title{
Role of colours in historical buildings preservation
}

Abstract: Colour has leading complex role in forming living environment. It brings information on many levels of perception and completes aesthetic value of the objects that surround us. Contemporary researches reveal that colours can be observed as a means to manipulate inhabitants' thermal, light, acoustical comfort and space configuration and it is a growing tendency in building and urban design. The article studies the role of colour in historic buildings and to what extent it can be altered during the preservation process according to its properties and to society perception. Data from survey upon specific historical buildings conducted by the team is analysed and compared with results from external researches. Aspects of historical building colour are specified and conclusions are made. Practical recommendations are defined.

Keywords: historic building, colour, preservation, urban development, living comfort.

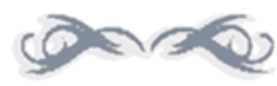

\section{Introduction}

Colour has leading complex role in forming living environment. It brings information on many levels of perception and completes aesthetic value of the objects that surround us. Contemporary researches reveal that colours can be observed as a means to manipulate inhabitants' thermal, light, acoustical comfort and space configuration and it is a growing tendency in building and urban design.

Studies on buildings' colours can be grouped in three groups:

- $\quad$ studies on historical buildings maintenance and managing policies;

- researches of historical building colour reconstruction as part of overall building's physical reconstruction;

- researches based upon contemporary discoveries of colours' optic, physical, physiologic and psychological qualities upon peoples' perception.

There are few to none studies of the role of historical buildings' colours as a complex task to preserve their historical authenticity and to contribute to improving their living comfort at the same time. 
The study purpose was to define the degree of original historical building colour's change in order to preserve its authenticity and to meet the requirements of the contemporary living environment.

Historical buildings are the standing memory of urban development. They represent complex historical aspects and require complex approach in their preservation. Using their potential for area regeneration and improvement becomes a priority in sustainable development.

The recent research is part of scientific project for colour application for improving living comfort. The article is focused on the role of colours in historical buildings preservation.

Data from study conducted by the research's team is compared with conclusions and results from similar studies. 91 people participated in the study -72 students, 14 lecturers and 5 members of the administration staff. They were shown pictures series of 22 buildings in Bulgaria (Figure 1; Figure 2) classified as monuments of national, regional and ensemble significance (National institute for immovable cultural heritage, 2020). Samples were chosen by category "architectural-constructive", aged 50-150 years, in sound physical condition and still occupied. Parameters set is based on similar topic research (Shannon, 2014). The questions were divided according to their relevance to the buildings' significance, vision and potential.

First researches of historical buildings colour design date back to the early $20^{\text {th }}$ century (Taylor et al., 1994). The importance of colours for inhabitants' comfort and their contribution to the creation of an aesthetic urban environment are known from deep antiquity. Colours have always been actively involved in all areas of architecture - details, interior design, facade design, urban and park environment.

The development of technologies and research methods provide new data on the participation of colours in the urban environment. Active application of colours even in epochs, which are associated with the monochrome of the main building material, cleared of nonpermanent covering layers, is revealed.

In previous research authors differentiate colours in two groups according to the role they play in the living environment - traditional and contemporary.

1.1 Traditional role of colours in the living environment

Traditional roles of colours are to carry information about the surrounding objects, to bring aesthetic value, to signal and denote important objects and zones and to carry a symbolic meaning.

\subsection{Contemporary colour application role}

Modern research reveals colour properties which determine new application possibilities. The ability to influence the perception of objects and spaces leads to colour application in order to visually complement and alternate the living environment characteristics. The application of colours according to their reflective properties assists the distribution of light and the accumulation of heat from solar electromagnetic energy by building elements. Most contemporary trend is the application of colours according to their physiological and psychological impact on the inhabitants (Marinova, 2012).

\section{Facade colour of historical buildings}

\section{Façade colour as historical building main characteristic}


During the survey façade colours and colour schemes were pointed as historical buildings' memorable characteristic (78/91), together with specific details (73/91) and architectural/constructive forms (81/91). Colour choice and colour schemes help distinguish buildings from one another. Also, colours were admitted as a means to recognize historical building period of construction.

\section{Aesthetic of historical building façade colour}

87 participants agree that historical buildings have distinctive aesthetics as a combination size, details, specific forms, materials and colours.

Historical buildings were admitted to be ones in which colour is more "visible" due to smaller façade openings (73/91). Also, historical buildings complexes are, unlike modern buildings, defined as harmonic for their similar colour scheme and façade design.

Such appreciation is due to the lack of colour satiation, typical for modern cities. "In the study of old cities, harmonious image of the city is recognizable. In these cities, feeling of being in a space with strong identity is experienced. Memorable and original spaces are adapted to the climate and culture of the people because of using the natural and native colours and materials. Therefore, each city had its own colour identity and was distinguished from other cities." (Khalilia, 2019)

\section{Historical building façade colour's informative role}

More than half of the participants admit they use such historical buildings as wayfinding benchmark and colour is most helpful in the process. Also, all the participants agree that the way colour was applied signifies the building as belonging to particular period or place.

\section{Historical building façade colour's symbolic role}

Often colour of historical buildings has history of its own. In some buildings colouring symbolized the financial prosperity of their owner who was at same time benefactor of the community. Examples of such historical building colouring of are Renaissance houses in Ancient Plovdiv, Bulgaria (Figure 1).

In other cases, such as buildings in the city of Jodhpur, India, colour reveals a local tradition of colouring.

Other symbolical application of historical building façade colour is mainly in buildings built for public purposes. Buildings from the end of the $19^{\text {th }}$ and beginning of the $20^{\text {th }}$ centuries are coloured in yellow, which symbolizes gold and therefore prosperity.

\section{Historical building façade colour as a way to improve living comfort}

In previous researches authors had reached the conclusion that traditional colouring of façade walls contributes to building energy efficiency. The facades of buildings in areas with long periods of sunshine are traditionally painted in light tones to reflect bigger part of solar radiation and thus to protect the main constructive elements and to keep cool indoor microclimate. In areas with lack of solar energy the preference is for darker facade colours (Marinova, 2012).

Table 1 reveals that façade colours of historic buildings meet most of the traditional and modern requirements and therefore no need for change is present (Table 1).

\section{Changing historical building façade colour}

85 of the participants wouldn't agree with colour change even if current one isn't the original building colour. Habituation to it was shown as explain (76/91). 69 of the participants would agree with change of colour during historic building preservation if new one's shade and hue are 
close to the previous and 87 agree for change of the material of the covering layer in order to better protect the main construction and to improve energy efficiency.

In conclusions of this chapter, it should be noted that historical building colour is part of their uniqueness, serves as a landmark and represents technologies, typical for the period of the construction. Façade colours of historic buildings are admitted to have leading role in forming their identity. They meet most of traditional and contemporary requirements toward colour design - to give information, to create aesthetics, to signify building's important characteristics, symbolize society importance and even contribute to energy efficiency.

Society preference is that during historic building's preservation colour should remain as is or with little difference in hue, saturation or value.

\section{Interior colour of historical buildings}

Due to the technological constraint historical buildings have smaller façade openings. This causes less solar radiation and therefore insufficient natural light and thermal gain to be generated in historic buildings' rooms. Survey participants evaluate interior images as "dark" or "twilight" (72/91).

However, historic building interior colour design was admitted as not so publically important. Exception was agreed for historic buildings with museum function where preserving interior's original view is of high importance for society. 73 of the participants agree to colour change in order to improve living comfort; a condition was defined for specific details to be preserved. Colours that can be perceived both as modern and historical (Modern Paint Colours That Work Surprisingly Well in Old Houses, 2016) and materials based on natural elements and modernized traditional technologies (Seeing the Past in Colour, 2015; Painting Historic Interiors, 2013) were appreciated (84/91).

In conclusions of this chapter, it should be noted that according to society historic house's interior colour design is not of such public value. Using colours according to their optical, physical and physical and psychological qualities in order to improve living environment is appreciated.

\section{Conclusion}

It is important when preserving, historical building façade colour or colour scheme is to be accept as it is or with little alternation. Façade colouring has characterising, aesthetic, informative and symbolic role and also contributes to energy efficient properties of the building. The main improvement should be through the covering materials, though they should be applied with respect to the original façade design.

Interior colour of preserved historic buildings can undergo significant change in order to create better living conditions through application of colours and materials that mitigate spaces' disadvantages and improve thermal absorption and light distribution.

\section{Acknowledgments}

The studies in this report are funded by science-research project №11, order № 256 / 27.05.2020. The authors express their gratitude to VSU "Lyuben Karavelov", Bulgaria. 


\section{$\infty x$}

\section{References:}

Khalilia, R. (2019). The role of colour in sense of place: Tajrish and Hassan Abad Squares. Tehran, Milano: Politecnico di Milano, Master thesis.

Marinova, I. (2012a). Colour properties as a means of improving living environment comfort. International Jubilee Scientific and Applied Conference 70 Years UACEG, Report Collection, 207-212. Sofia.

Marinova, I. (2012b). The role of the colour solution of the architectural environment in improving energy efficiency. XII International Scientific Conference, VSU "L. Karavelov", Collection of Reports, 2, 64-69. Sofia.

Modern Paint Colours That Work Surprisingly Well in Old Houses. (2016, December 10). https://www.countryliving.com/home-design/colour/g3033/paint-colours-for-oldhouses

National institute for immovable cultural heritage. (2020, September 26). http: $/ /$ mc.government.bg/page.php?p $=58 \& s=429 \& \mathrm{sp}=430 \& \mathrm{t}=244 \& \mathrm{z}=725$

Painting Historic Interiors. (2013, July 13). https://www.nps.gov/tps/how-topreserve/briefs/28-painting-interiors.htm

Seeing the Past in Colour: An introduction to architectural paint research for historic interiors. (2015, April 16). https://www.buildingconservation.com/articles/paint-research/paintresearch.htm

Shannon, S. (2014). Summary of "A Survey of the Public: Preference for Old and New Buildings, Attitudes about Historic Preservation, and Preservation-Related Engagement". Department of Heritage Conservation, University of Southern California, Los Angeles, CA, Master Thesis.

Taylor, Jr., Thomas, H. Jr., \& Nicholas, A. (1994). Colonial Williamsburg Colours: A Changing Spectrum. In Roger W. Moss. (Ed.). Paint in America: The Colours of Historic Buildings. New York: John Wiley \& Sons, Inc. 


\section{Appendix}

Table 1. Comparison of colour role

\begin{tabular}{|l|l|}
\hline \multicolumn{1}{|c|}{ Living environment } & \multicolumn{1}{c|}{ Historical buildings } \\
\hline surrounding objects & $\begin{array}{l}\text { one of building's main characteristic, helps } \\
\text { distinguish one building from another }\end{array}$ \\
\hline aesthetic value & $\begin{array}{l}\text { distinctive aesthetics, adapted to the } \\
\text { climate and culture }\end{array}$ \\
\hline $\begin{array}{l}\text { signifying role, } \\
\text { functional zones marking }\end{array}$ & $\begin{array}{l}\text { wayfinding benchmark, historic period } \\
\text { signification }\end{array}$ \\
\hline symbolic meaning & public value, economical wealth, \\
\hline forms' visual alternation & - \\
\hline light distribution and heat storage & $\begin{array}{l}\text { climate adapted coloring to absorb/reflect } \\
\text { solar radiation }\end{array}$ \\
\hline $\begin{array}{l}\text { physiological and psychological impact } \\
\text { on the inhabitants }\end{array}$ & - \\
\hline
\end{tabular}




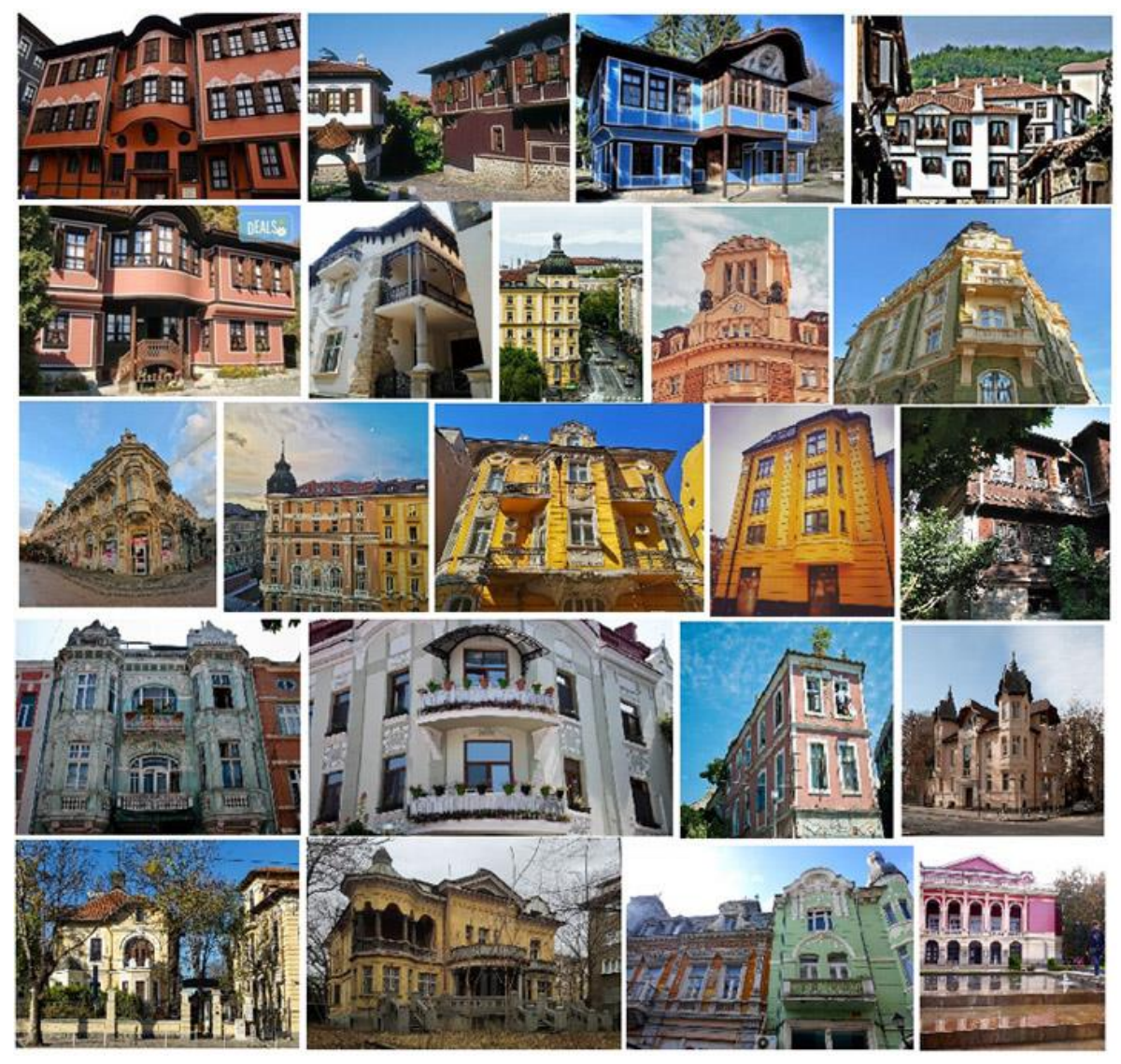

Figure 1. Historic buildings facades

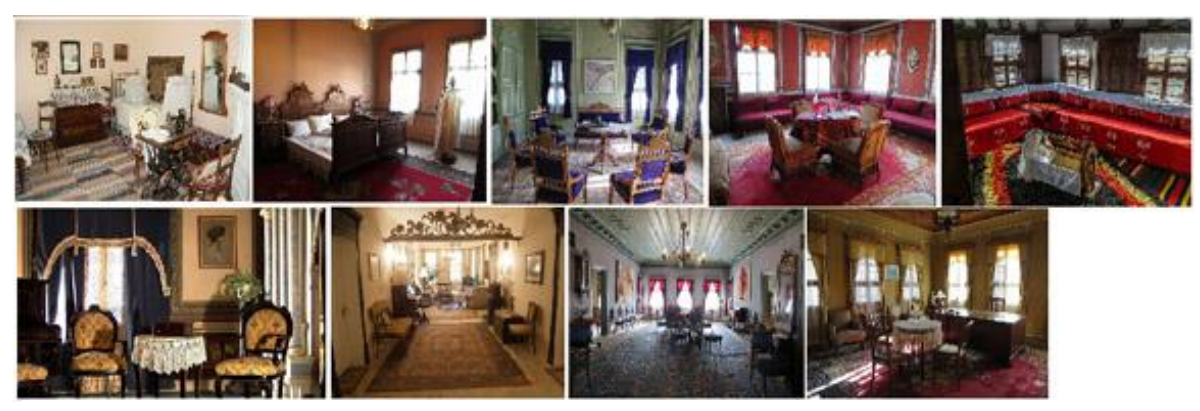

Figure 2. Historic buildings interiors 